\title{
PW10-06
}

\section{THE POSTER OF POSTERS: EVALUATION OF THE 20TH ECNP CONGRESS}

\section{F. Versonnen}

Department of Clinical Research, Vincent Van Gogh Institute for Psychiatry, Venray, The Netherlands

Basic and clinical research are both of importance for psychiatry. In psychiatric care, both neurobiological and psychosocial underpinnings of clinical diagnosis and treatment. To come to a meaningful intervention, one is in need of different levels of explanation. Moreover, in a clinical setting, an integration of the so called Evidence Based Medicine (EBM) and Narrative Based Medicine (NBM) seems to be most appropriate. Basic research is sometimes seen as 'more scientific' and this may be reflected by granting more awards for these posters. A simple quantitative analysis is done by comparing the basic and clinical posters at the 20th ECNP Congress in Vienna. The total of submissions, the basic versus clinical 'awards'- and Odds-ratio are calculated. Some corrections are needed. First, 10 psychology posters, were classified as basic and were reattributed to the clinical category. Second, after a qualitative analysis and correction for preclinical narratives or basic research methods for 7 awarded clinical posters, they were reclassified to the basic science category. All awarded basic posters were labeled correctly. After this double correction the Odds ratio was calculated. A total of 725 posters were submitted, 426 clinical and 299 basic. Fifty posters were awarded. The Odds ratio of getting an award was 5,8 in favor of basic science posters. This is an expression of the current undervaluation of clinical research. 